\title{
Endoscopic Third Ventriculostomy : Success and Failure
}

\author{
Chandrashekhar E. Deopujari, M.Ch., Vikram S. Karmarkar, DNB, Salman T. Shaikh, M.S. \\ Department of Neurosurgery, Bombay Hospital Institute of Medical Science, Mumbai, India
}

Endoscopic third ventriculostomy (ETV) has now become an accepted mode of hydrocephalus treatment in children. Varying degrees of success for the procedure have been reported depending on the type and etiology of hydrocephalus, age of the patient and certain technical parameters. Review of these factors for predictability of success, complications and validation of success score is presented.

Key Words : Hydrocephalus · Ventriculostomy · Cerebrospinal fluid shunt.

\section{INTRODUCTION}

Hydrocephalus is a spectrum of conditions where there is a mismatch of cerebrospinal fluid (CSF) production and absorption, with resultant enlarged ventricles. There are many proposed classifications for hydrocephalus. Most commonly in use is the obstructive (non-communicating) and the communicating type $\mathrm{e}^{7}$. In the obstructive variety, the block is proximal to the arachnoid granulations and may be further classified into intraventricular or extraventricular ${ }^{41)}$. The communicating type develops because of defective absorption at the arachnoid granulation. Other classifications include etiologic classification viz. tumor related, post-hemorrhagic, postinfectious, post-traumatic, ex vacuo and normal pressure hydrocephalus.

Over a hundred years ago, pioneers like Dandy, Lespinasse, and Mixter attempted to treat hydrocephalus with open and endoscopic third ventriculostomy (ETV), choroid plexectomy and fulguration. Their poor results prompted the medical and neurosurgical community to look for other solutions. This came in the form of shunts devised by Nulsen and Spitz working with an engineer Holter in the $1950{ }^{3}{ }^{44)}$. This technology was immediately accepted and has further evolved and matured to become the standard of care for all types of hydrocephalus. However, in spite of several innovations and technical modifications, shunts are not without complications and have remained a constant source of concern for the child, parents and the family. Along with improvements in endoscope and camera technologies, desire of shunt freedom has led to a resurgence of ETV techniques.

ETV is recommended as the choice of treatment for obstructive hydrocephalus in many centers now. Though the immediate success of this procedure can be determined by clinical improvement and absence of need for a further surgical procedure, there are several concerns in assessing the outcome. The influence of age, etiology and previous shunting has been frequently reported and predictive scores and guidelines have been described. However, major worrisome factors

- Received : February 16, 2017 •Revised : March 28, 2017 •Accepted : March 29, 2017

-Address for reprints : Chandrashekhar E. Deopujari, M.Ch.

126B, 1st floor, Medical Research Centre Building, Bombay Hospital, 12, Marine Lines, Mumbai 400020, India

Tel : +91-9819831736, Fax : +91-022087805, E-mail : d.chandrashekhar11@gmail.com

This is an Open Access article distributed under the terms of the Creative Commons Attribution Non-Commercial License (http://creativecommons.org/licenses/by-nc/4.0) which permits unrestricted non-commercial use, distribution, and reproduction in any medium, provided the original work is properly cited. 
for long-term outcome are the suboptimal reduction in ventricular size and resultant failure of restoration of cortical mantle as well as persistent large head. Furthermore, the place of repeat ETV and other endoscopic solutions in complex hydrocephalus are being evaluated. We have tried to review these factors in available literature with comments from our experience.

\section{DISCUSSION}

\section{Success of ETV}

The simplest definition of success of ETV is "freedom from a shunt".

Evolution of ETV for hydrocephalus has been a lesson in history of how a neurosurgical procedure can and should be evaluated with technical innovations and better case selection as described by Schmitt and Jane ${ }^{44)}$.

Patient parent support groups like the Hydrocephalus Association in the USA have defined the success of the procedure thus ${ }^{15)}$ - "Success in terms of this procedure is usually considered (by patients and doctors alike) to be avoiding a shunt in a patient who would otherwise require one. Most doctors would categorize ETV as successful if a patient later shows clinical evidence of normal intracranial pressure (ICP) and structural evidence of stable or decreased ventricular size. If a patient was previously shunted, the shunt must be either removed or proved nonfunctional to demonstrate success."

\section{DETERMINANTS OF SUCCESS}

Several factors contribute to the success of the ETV.

\section{Clinical selection for ideal candidate}

Age greater than 6 months with aqueduct stenosis or tectal tumor and no previous shunting can be considered as an ideal candidate for ETV. ETV works best as a primary procedure in obstructive hydrocephalus without evidence of prior infection or hemorrhage (Fig. 1). Patients with communicating hydrocephalus are usually not good candidates for this technique although some groups claim success ${ }^{20,40)}$.

\section{Radiologically ideal ETV candidate}

Presence of clear evidence of ventricular non-communication i.e. obstructive pattern of hydrocephalus, anatomic obstruction at the aqueduct and/or lack of aqueduct flow void on T2 magnetic resonance imaging (MRI) and a thinned out floor of the third ventricle with a downward bulge are good indications for ETV. Width of foramen of Monroe should be sufficient to accommodate the endoscope $(7 \mathrm{~mm}$ for rigid scope, $4 \mathrm{~mm}$ for flexible scope).

\section{Technical considerations: Intraoperative criteria for ideal ETV candidate}

The perforation of the floor should preferably be made without application of an energy source. Openings made using a monopolar energy source are believed to induce an inflammatory response which may close the stoma. Some groups have used a contact laser to create the opening. A high power Nd-YAG or lower powered diode lasers have been used $^{8}$. These groups have shown favorable results. Our policy is to use the blunt end of a monopolar probe without application of any energy, to make the stoma. The stoma size should be adequate, usually around $3-4 \mathrm{~mm}$ in diameter. A rough

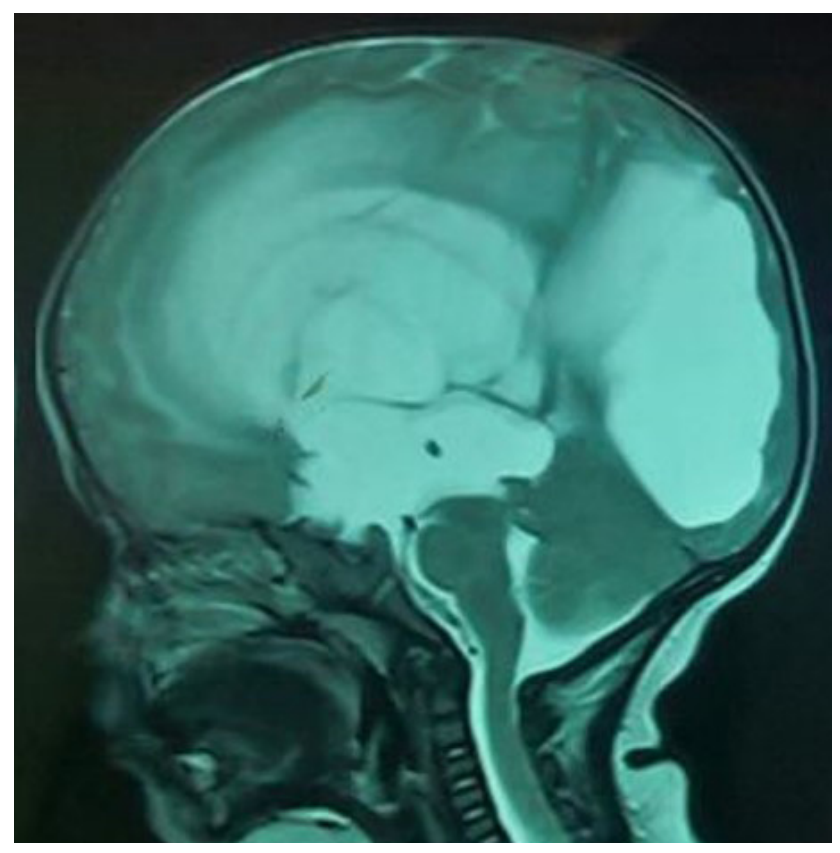

Fig. 1. An ideal candidate for ETV at six and half months of age due to congenital aqueduct stenosis with dilated third ventricle, floor bulging down into the interpeduncular cistern and adequate pre-pontine space. ETV : endoscopic third ventriculostomy. 
estimate of adequacy is the ability to insert the scope through the stoma into the pre-pontine cistern. The stoma size is enlarged with a 3 or 4 Fr Fogarty balloon catheter. This is an important step during the procedure. An additional advantage is that minor capillary bleeding can be halted by inflating the balloon to tamponade the bleeding vessels. Visualization of perforating branches of the basilar artery along with opening up of any second membrane is routinely considered satisfactory enough.

A study of 403 patients by Warf and Kulkarni ${ }^{54)}$ observed that scarring at the cisterns more than doubled the risk of ETV failure and an open aqueduct increased the risk of failure by $50 \%$. The success rate has been shown to be directly proportional to the experience of operating surgeon and volume of cases tackled by the pediatric centre apart from the above mentioned factors ${ }^{13)}$. Usually at the end of the procedure, with the irrigation turned off, the floor of the third ventricle can be seen pulsating or flapping with arterial pulsations and the respiratory movements.

In all cases of secondary ETV or in cases there has been some bleeding during the procedure, an Ommaya reservoir and ventricular catheter are inserted for access. This is helpful in acute hydrocephalus due to blockage of the stoma.

\section{CRITERIA FOR DEFINING SUCCESS}

\section{Clinical}

This includes resolution of the preoperative signs of raised ICP i.e., improvement in the level of consciousness, resolution of eye movement abnormalities, resolution of headaches, stabilization or reduction in the head circumference and reduction of the fontanelle tension (in infants).

\section{Radiological}

On appropriate temporal follow up, criteria include decrease or stabilization of the ventricular size over a period of three months. Most marked change is noted in cases of acute hydrocephalus and in reduction in size of the third ventricle (i.e., by $25 \%)^{42}$. A $15 \%$ reduction in size of the third ventricle within 1 month is considered as a reliable indicator of favorable outcome $^{47)}$. Usually the extent of ventricular size reduction postoperatively is inversely proportional to the duration and mag- nitude of symptoms preoperatively ${ }^{46)}$. It has been noted that sometimes the ventricular size may not show a remarkable reduction on imaging post ETV as compared to post shunting. However, this need not be a reflection of raised ICP. Conversely reduction in ventricular size post ETV may or may not indicate a successful procedure as it has been found to reduce marginally in both settings. A greater reduction in mean ventricular size (16\% vs. $7 \%$ ) was observed by Kulkarni et al. ${ }^{27)}$ in successful ETV outcomes as compared to ETV failures. Twenty nine children who underwent ETV were followed up here. Flow voids were present in $94 \%$ of successful cases and absent in $75 \%$ of failures. Evans ratio, third ventricle index, cella media index (ratio of the biparietal diameter of skull to maximum external diameter of lateral ventricles at the central part of lateral ventricles) and ventricular score has been found to decrease in favorable outcome cases and increase in failed ones $^{43)}$.

Special MRI sequences like the phase contrast cine flow study (Fig. 2), heavily weighted T2 studies and more recently 3D-SPACE sequences are being used to assess patency of the stoma $^{1)}$. Sometimes, a computed tomography (CT) contrast dye study may be used if one has ventricular access through an Ommaya reservoir or a similar device. Here radiopaque

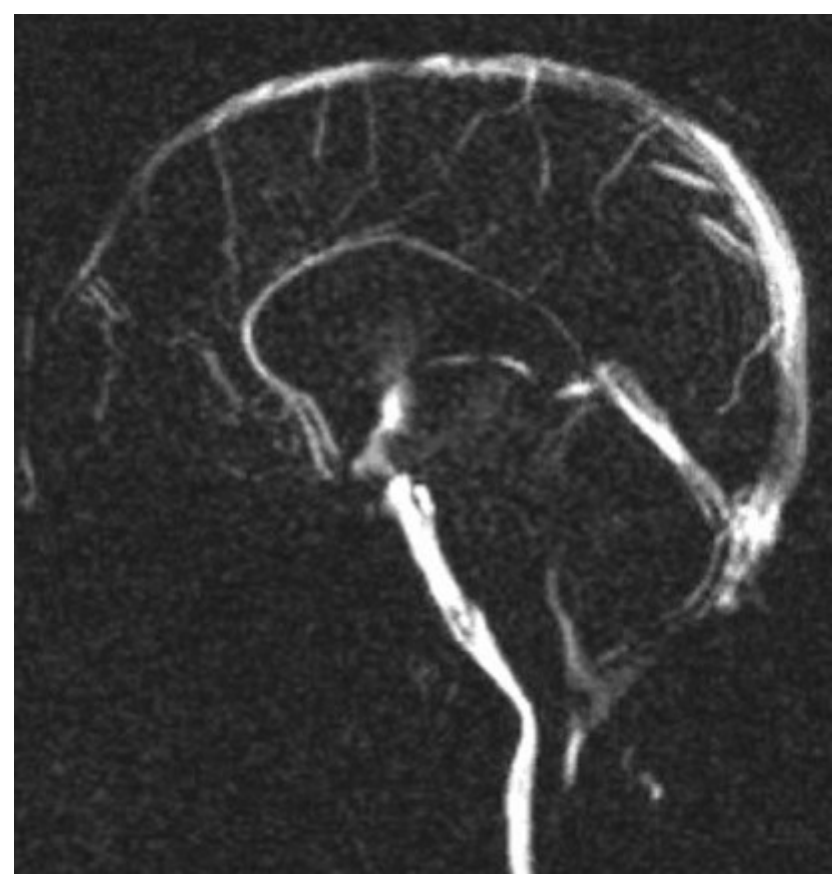

Fig. 2. CSF flow across the stoma post ETV seen in cine flow MRI sequence for evaluation of ETV success. CSF : cerebrospinal fluid, MRI : magnetic resonance imaging, ETV : endoscopic third ventriculostomy. 
contrast is injected into the ventricles via the reservoir and sequential CT scans in time reveal the migration of the dye from the lateral ventricle to the brainstem cisterns and absorption in case of a patent stoma.

Thus clinical correlation is more important than radiological correlation to determine successful outcome. Imaging does provide a reliable mean to positively predict the patients' course but its use as a sole entity is inadequate ${ }^{5)}$.

\section{COMPLICATIONS AND ITS AVOIDANCE}

Complications include bleeding from the walls of the third ventricle. This is usually temporary and stops with irrigation and sometimes balloon tamponade. Larger vessel bleeding like perforators or basilar artery branches can lead to significant morbidity. Basilar artery aneurysms/pseudo-aneurysms may result from this hemorrhage. Hypothalamic injury may result from eccentric perforations. This again has a very high morbidity. Perforation of the floor in ETV can theoretically affect the hypothalamo-pituitary axis leading to hormonal disturbances. Fritsch et al. examined 20 such patients but found no clinical relevance as such. Further studies are needed to ascertain the endocrine outcome post $\mathrm{ETV}^{18)}$. Cranial nerve injury can result from improper placement of the balloon catheter and inflation causing stretch of the nerves. Cardiac arrest is a possibility in case of over inflation of the balloon accompanied by failure of egress of the irrigating fluid. CSF leak and electrolyte imbalance can be challenging complications to treat. Post-operative CSF leak from the wound is an indicator of poor outcome. Subdural effusions are also known to occur. Occlusion of the site of ETV leading to sudden death is a rare occurrence but has been known to occur ${ }^{11}$. Closure of the stoma secondary to gliosis usually presents within 2 years unlike acute shunt malfunction which may manifest till many years post shunt insertion necessitating the need for a longer follow-up. An Ommaya inserted in select high risk cases may turn out to be life-saving by helping to achieve a rapid ventricular access to negate the non-patent stoma ${ }^{32)}$.

\section{ETV SUCCESS SCORE AS A PREDICTIVE TOOL}

The most commonly used tool to predict the chances of a successful ETV are the Endoscopic Third Ventriculostomy Success Score (ETVSS). This was developed by Kulkarni et al. $^{29)}$. They used logistic regression techniques to predict the success of ETV with relation to age of the patient, etiology for hydrocephalus and previous shunting history. The resulting ETVSS has a range from 0 (very poor success) to 90 (very high success). The score approximates the percent chances of successful outcome at six months following procedure. Age ranges from less than one month, one month to six months, six months to a year, one year to ten years and beyond ten years are given progressively higher scores. Etiology includes post infection, myelomeningocele, intraventricular hemorrhage, non tectal tumors. Aqueduct stenosis and tectal tumors get sequentially better scores. Previous shunt surgery or primary procedure forms the third arm of the scoring system. The final ETVSS is the addition of the age score, etiology score and shunt score. This study included outcomes at 6 months follow up. In a follow up study across all ETVSS groups ${ }^{28)}$, they concluded that as the postsurgical time progresses, the risk of ETV failure reduces in comparison to that of shunt failure. In 2011, the same group of authors also reviewed literature published over 20 years and inferred that the ETVSS can closely predict the actual ETV success rate ${ }^{30)}$.

\section{Age as a determinant}

The success rate of ETV in 21 patients less than two years of age was analyzed by Baldauf et al. ${ }^{3)}$. It was found in this study that the success rate of ETV in children less than two years of age suffering from obstructive hydrocephalus depends on age and etiology with an overall success rate of 43\%. In infants, ETV was successful in $37.5 \%$ of cases. On analyzing ETV done for 41 hydrocephalus patients younger than two years, Sufianov et al. ${ }^{50)}$ observed that ETV was successful in $71.4 \%$ of children between one to two years and in $75.0 \%$ of children less than one year. They concluded that success of ETV in this group of patients (<two years) depends on the thickness of the floor of third ventricle and the age at which hydrocephalus presented.

He et al. ${ }^{22)}$ have reported sixteen successful ETV procedures done out of seventeen attempted cases of infantile hydrocephalus of varied etiology. A retrospective analysis by Jernigan et $\mathrm{al}^{24)}$ of 5,416 infants with hydrocephalus who underwent CSF diversion either in the form of shunting or ETV observed a failure rate of $64 \%$ after ETV, higher than the $40 \%$ failure rate 
seen post shunting. This rate was even more pronounced if ETV was done within 3 months of birth.

Ogiwara et al. ${ }^{39)}$ retrospectively analyzed 23 patients less than six months of age who were treated with ETV. They were of the opinion that ETV can be considered as the primary treatment for hydrocephalus in children above three months of age.

A significant improvement in our understanding has been contributed by the preliminary results published by The International Infant Hydrocephalus Study Group ${ }^{31)}$; This prospective, multicenter comparison of ETV and shunt success in patients less than two years of age has analyzed 158 patients and their results suggest that shunting has a superior success rate as compared to ETV (66\% vs. $88 \%$ at age of six months).

It seems that ETV has a higher possibility of success than what is described in the ETVSS, especially above the age of 3 months.

\section{Etiology as a determinant}

Within the parameters of age, etiology may also play a significant role.

Koch and Wagner ${ }^{26)}$ found poorer results of ETV in cases of obstructive hydrocephalus other than aqueduct stenosis and in very young age group of patients.

In the common scenario prevalent in South Asia and Africa, of post-meningitis hydrocephalus, particularly associated with tuberculosis, several studies have been described for ETV. ETV has been shown to have a success rate between $60-85 \%$ in most series published ${ }^{16)}$. ETV helps to divert the CSF to areas which were previously inaccessible and clears exudates from the areas which had impaired absorption, thus helping to improve drug delivery ${ }^{25)}$. Chugh et al. ${ }^{6)}$ suggested in 2009 that ETV can be considered as the primary interventional modality in patients with tuberculous meningitic hydrocephalus especially those with a longstanding disease.

ETV in spina bifida patients more than 6 months of age after shunt failure has been shown to have a good long term success (approximately 80\%) ${ }^{52)}$.

ETV in Dandy Walker malformation can be an effective means to achieve reduction in hydrocephalus and is a recommended line of treatment ${ }^{23)}$.

Hydrocephalus in Chiari 1 malformation is a known entity with a complex etiology which is a matter of great debate. However the use of ETV in Chiari 1 malformation is gather- ing pace mainly because it causes reduced hampering of the physiological pathways of CSF flow and absorption ${ }^{9)}$.

ETV for craniosynostosis has a relatively higher failure rate. Out of eleven patients of craniosynostosis with hydrocephalus treated by Di Rocco et al. ${ }^{10)}$, seven patients were successful in the outcome and shunting was required for the remaining four. A closer monitoring is recommended in these scenarios.

In terms of ETV in tumoral hydrocephalus; in a study of thirty pediatric patients developing hydrocephalus amongst 104 who underwent posterior fossa surgery, ETV was found to have a success rate of more than $90 \%$ and has been recommended as the ideal treatment for hydrocephalus in such cas$\mathrm{es}^{51)}$. ETV for pineal region tumours is regarded as the primary line of intervention with the advantage of not only relieving hydrocephalus but also providing window for biopsy, CSF analysis and to inspect for tumor seedlings and dissemination if any ${ }^{38)}$.

ETV is also shown to have similar if not better results to shunting in cases of normal pressure hydrocephalus and can be recommended as a primary line of treatment ${ }^{19)}$.

\section{Past history of shunting as a determinant}

Labidi et al. ${ }^{33)}$ studied the ETVSS in 168 patients more than two years of age recently. They found the ETVSS to be more useful in situations where $60 \%$ or $70 \%$ success rate is the threshold for preferring ETV to CSF shunt. Past history of shunting and age was not found to be associated with poor outcome unlike the post-hemorrhage and post-infectious causes of hydrocephalus which correlated with reduced success rates post ETV. Melikian and Korshunov ${ }^{37)}$ observed that ETV done in cases of shunt malfunction in obstructive hydrocephalus gave a $70 \%$ chance of long term shunt free status.

Secondary ETV may be done in the form of repeat endoscopic ventriculostomy for treatment of failed ETV in obstructive hydrocephalus due to stoma closure (Fig. 3A-C). Mahapatra et al. ${ }^{35)}$ in a study of 32 cases of failed ETV who underwent re-ETV suggested that secondary ETV is an effective procedure and can be offered to the patient prior to shunt insertion. Siomin et al. ${ }^{49)}$ reported an increase in ETV efficacy in post-hemorrhagic hydrocephalus from $60.9 \%$ for primary ETV to $100 \%$ for secondary ETV. This is attributed to better maturation of arachnoid villi over a period of time after recovery from the acute insult.

ETV following shunt malfunction has also been shown to be 

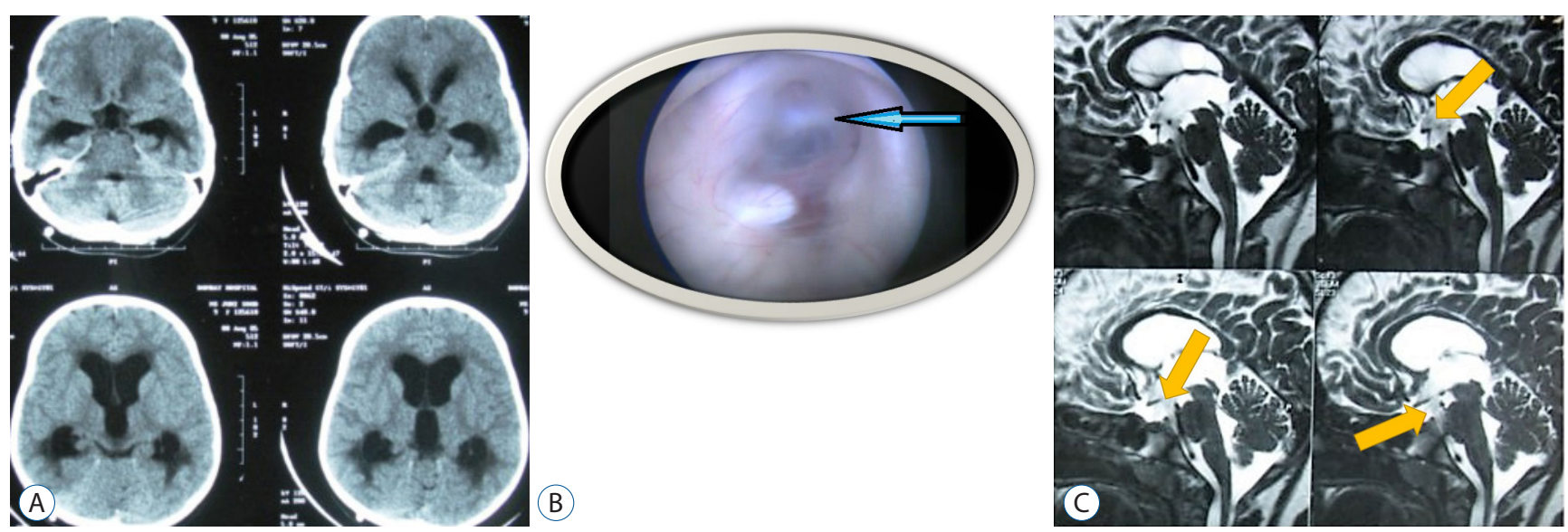

Fig. 3. A : Primary ETV failure in a child with post tuberculous meningitic hydrocephalus presenting with acute deterioration in emergency. B : Stenosed stoma with scar in the floor of the third ventricle (arrow) during secondary ETV. C: MR image showing restoration of CSF flow across the stoma (arrows) post secondary ETV. Patient has not needed any further procedure in eleven years of follow-up with a good intellectual outcome. ETV : endoscopic third ventriculostomy, MR: magnetic resonance, CSF : cerebrospinal fluid, CT : computed tomography.

an effective treatment for shunt failure. Varying reports in the literature cite an ETV success rate of approximately $65-70 \%$ in cases of shunt malfunction ${ }^{14,36}$.

Secondary ETV has been used in shunt infections. Although the procedure does not obviate the need for later shunt implantation, it is shown to delay the subsequent procedures ${ }^{48}$. When performing a secondary procedure, some studies recommend removal or blockage of the malfunctioning shunt. This is shown to increase the longevity of the procedure.

In our experience, ten cases of shunt malfunction underwent ETV at a mean age of nine years; seventy percent success rate was seen with secondary ETV for a single procedure. Two of the remaining patients responded to repeat ETV while one with patent stoma required shunt insertion. We found that the follow up period required is much longer than for a primary procedure, as failures were seen even two years following secondary ETV.

Other endoscopy procedures like septostomy may help a previously shunted patient in cases of unilateral ventricle being drained by shunt due to foraminal block (Fig. 4A, B). Aqueductoplasty has, however, not been popular because of its high morbidity ${ }^{45)}$.

\section{LONG TERM NEUROPSYCHOLOGICAL OUTCOME}

A study of thirteen patients with non-communicating hydrocephalus with concurrent cognitive dysfunction by Hader et al. ${ }^{21)}$ showed significant improvement (approximately 70\%) in at least one clinical entity post ETV. It has not yet been conclusively proven that shunting gives a better neuropsychological outcome over long term as compared to ETV ${ }^{2}$. The long term intellectual and psychological outcomes are also currently being evaluated by the International Infant Hydrocephalus Study group ${ }^{31)}$.

\section{VALIDATION OF ETVSS}

Various studies have validated this scoring system to predict success of the procedure. Durnford et al. ${ }^{12)}$ externally validated the ETVSS by retrospectively comparing actual success at both 6 and 36 months in 166 patients of a mean age of 39 months. They concluded that the ETVSS closely predicted the overall long term success rates in high, moderate and low risk groups. Breimer et al.") studied 104 patients of hydrocephalus less than 18 years of age and found the ETVSS to be a more reliable indicator of short term success rather than long term one. Foley et al. ${ }^{17)}$ consider the ETVSS to be an adequate tool for individual assessment of patients and for charting their prospective course with respect to ETV response.

\section{ETV VS. SHUNTING}

Tuli et al. ${ }^{53)}$ first showed in 1999 in their study of 242 cases, 

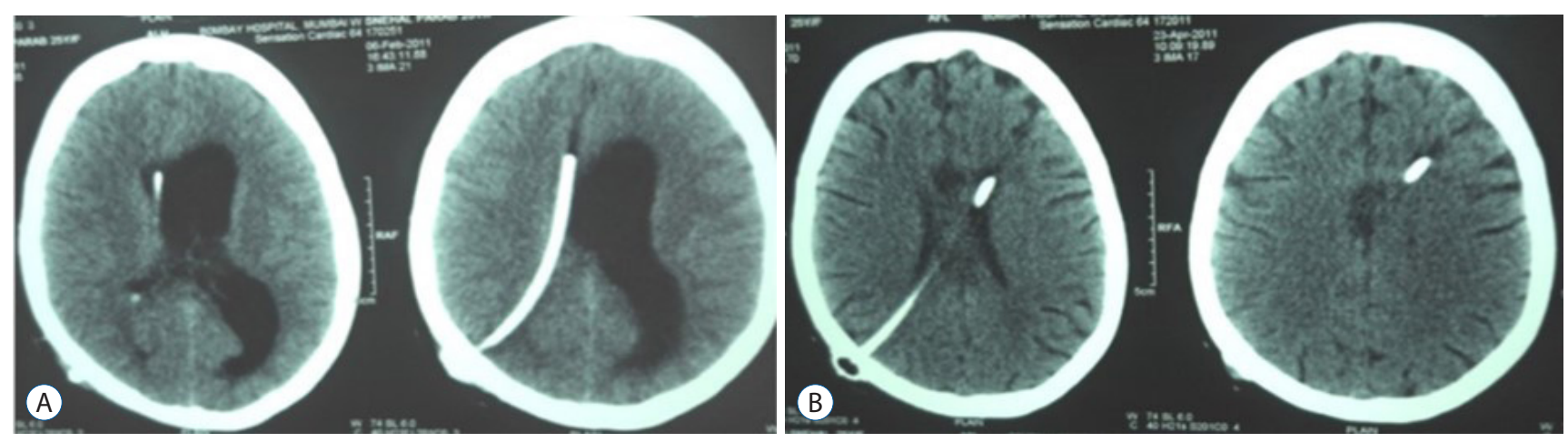

Fig. 4. A : Post shunting brain CT images showing unilateral and asymmetrical drainage of CSF. B : Post endoscopic septostomy brain CT images showing resolution. CSF : cerebrospinal fluid, $\mathrm{CT}$ : computed tomography.

that results were comparable between shunting and ETV (44\% vs. $45 \%$ ). A multicenter study comprising over 1000 patients by Kulkarni et al. ${ }^{28}$ has studied this subject in further detail while devising the ETVSS. In the recently published systematic review by Limbrick et al. ${ }^{34)}$ quoting more than 100 articles, evidence suggests that both shunting and ETV provide an equivalent result in most cases of pediatric hydrocephalus.

However shunt may not be the panacea and may have certain contraindications as evidenced by one of our patients recently. A 20 year boy presented to us with history of extrusion of shunts through the skin three times in the past following shunt revision done sixteen times. He was diagnosed as a case of silicon allergy and underwent ETV as no shunt option was left. Obstructive pattern of hydrocephalus was the only predictive factor. No landmarks were seen on the third ventricular floor. Navigation guided ETV was performed. The patient has been clinically stable during the last two years.

\section{CONCLUSION}

ETV has further increased our understanding of hydrocephalus in many ways and has been a useful adjunct in management of pediatric hydrocephalus.

With increasing use of this method, the indications are getting refined. The prediction of ETV success and failure is possible today for immediate success and with more experience can be applied as a long term outcome indicator. Though shunting is a useful tool in treatment of hydrocephalus, and is more widely applicable than ETV for pediatric hydrocephalus, it may not be the first choice in selected cases where ETV gives comparable results with the distinct advantage of freedom from hardware and its associated risks.

\section{References}

1. Algin O, Ucar M, Ozmen E, Borcek AO, Ozisik P, Ocakoglu G, et al. : Assessment of third ventriculostomy patency with the 3D-SPACE technique: a preliminary multicenter research study. J Neurosurg 122 : 1347-1355, 2015

2. Azab WA, Mijalcic RM, Nakhi SB, Mohammad MH : Ventricular volume and neurocognitive outcome after endoscopic third ventriculostomy: is shunting a better option? A review. Childs Nerv Syst 32 : 775-780, 2016

3. Baldauf J, Oertel J, Gaab MR, Schroeder HW : Endoscopic third ventriculostomy in children younger than 2 years of age. Childs Nerv Syst 23 : 623-626, 2007

4. Breimer GE, Sival DA, Brusse-Keizer MG, Hoving EW : An external validation of the ETVSS for both short-term and long-term predictive adequacy in 104 pediatric patients. Childs Nerv Syst 29 : 1305-1311, 2013

5. Buxton N, Turner B, Ramli N, Vloeberghs $M$ : Changes in third ventricular size with neuroendoscopic third ventriculostomy: a blinded study. J Neurol Neurosurg Psychiatry 72 : 385-387, 2002

6. Chugh A, Husain M, Gupta RK, Ojha BK, Chandra A, Rastogi M : Surgical outcome of tuberculous meningitis hydrocephalus treated by endoscopic third ventriculostomy: prognostic factors and postoperative neuroimaging for functional assessment of ventriculostomy. J Neurosurg Pediatr $3: 371-377,2009$

7. Dandy $W$ : Internal hydrocephalus, an experimental, pathological and clinical study. Am J Dis Child 8 : 406-482, 1914

8. Devaux BC, Joly LM, Page P, Nataf F, Turak B, Beuvon F, et al. : Laserassisted endoscopic third ventriculostomy for obstructive hydrocephalus: technique and results in a series of 40 consecutive cases. Lasers Surg Med 34 : 368-378, 2004

9. Di Rocco C, Frassanito P, Massimi L, Peraio S : Hydrocephalus and Chiari 
type I malformation. Childs Nerv Syst 27 : 1653-1664, 2011

10. Di Rocco F, Jucá CE, Arnaud E, Renier D, Sainte-Rose C : The role of endoscopic third ventriculostomy in the treatment of hydrocephalus associated with faciocraniosynostosis. J Neurosurg Pediatr 6 : 17-22, 2010

11. Drake J, Chumas P, Kestle J, Pierre-Kahn A, Vinchon M, Brown J, et al. : Late rapid deterioration after endoscopic third ventriculostomy: additional cases and review of the literature. J Neurosurg 105(2 Suppl) : 118126, 2006

12. Durnford AJ, Kirkham FJ, Mathad N, Sparrow OC : Endoscopic third ventriculostomy in the treatment of childhood hydrocephalus: validation of a success score that predicts long-term outcome. J Neurosurg Pediatr $8:$ 489-493, 2011

13. Egger $D$, Balmer $B$, Altermatt $S$, Meuli $M$ : Third ventriculostomy in a single pediatric surgical unit. Childs Nerv Syst 26 : 93-99, 2010

14. Brichtova E, Chlachula M, Hrbac T, Lipina R : Endoscopic third ventriculostomy in previously shunted children. Minim Invasive Surg 2013 : 584567, 2013

15. Hydrocephalus Association : Fact Sheet: Endoscopic Third Ventriculostomy. Available from : http://www.hydroassoc.org/docs/FactSheet_Third_Ventricular_Endoscopy.pdf

16. Figaji $A A$, Fieggen $A G$, Peter $J C$ : Endoscopic third ventriculostomy in tuberculous meningitis. Childs Nerv Syst 19 : 217-225, 2003

17. Foley RW, Ndoro S, Crimmins D, Caird J : Is the endoscopic third ventriculostomy success score an appropriate tool to inform clinical decisionmaking? Br J Neurosurg 14 : 1-6, 2016

18. Fritsch MJ, Bauer M, Partsch CJ, Sippell WG, Mehdorn HM : Endocrine evaluation after endoscopic third ventriculostomy (ETV) in children.

Childs Nerv Syst 23 : 627-631, 2007

19. Gangemi M, Maiuri F, Buonamassa S, Colella G, de Divitiis E : Endoscopic third ventriculostomy in idiopathic normal pressure hydrocephalus. Neurosurgery 55 : 129-134; discussion 134, 2004

20. Gangemi M, Mascari C, Maiuri F, Godano U, Donati P, Longatti PL : Longterm outcome of endoscopic third ventriculostomy in obstructive hydrocephalus. Minim Invasive Neurosurg 50 : 265-269, 2007

21. Hader WJ, Brooks BL, Partlo L, Hamilton M : Neuropsychological outcome after endoscopic third ventriculostomy. Can J Neurol Sci 41 : 729-734, 2014

22. He Z, An C, Zhang X, He X, Li Q : The efficacy analysis of endoscopic third ventriculostomy in infantile hydrocephalus. J Korean Neurosurg Soc 57 : 119-122, 2015

23. Hu CF, Fan HC, Chang CF, Wang CC, Chen SJ : Successful treatment of Dandy-Walker syndrome by endoscopic third ventriculostomy in a 6-month-old girl with progressive hydrocephalus: a case report and literature review. Pediatr Neonatol 52 : 42-45, 2011

24. Jernigan SC, Berry JG, Graham DA, Goumnerova L : The comparative effectiveness of ventricular shunt placement versus endoscopic third ventriculostomy for initial treatment of hydrocephalus in infants. J Neurosurg Pediatr $13: 295-300,2014$

25. Jonathan $A$, Rajshekhar $V$ : Endoscopic third ventriculostomy for chronic hydrocephalus after tuberculous meningitis. Surg Neurol 63 : 32-34; discussion 34-35, 2005
26. Koch $D$, Wagner $W$ : Endoscopic third ventriculostomy in infants of less than 1 year of age: which factors influence the outcome? Childs Nerv Syst 20 : 405-411, 2004

27. Kulkarni AV, Drake JM, Armstrong DC, Dirks PB : Imaging correlates of successful endoscopic third ventriculostomy. J Neurosurg 92 : 915-919, 2000

28. Kulkarni AV, Drake JM, Kestle JR, Mallucci CL, Sgouros S, Constantini S; Canadian Pediatric Neurosurgery Study Group : Predicting who will benefit from endoscopic third ventriculostomy compared with shunt insertion in childhood hydrocephalus using the ETV Success Score. J Neurosurg Pediatr 6 : 310-315, 2010

29. Kulkarni AV, Drake JM, Mallucci CL, Sgouros S, Roth J, Constantini S; Canadian Pediatric Neurosurgery Study Group : Endoscopic third ventriculostomy in the treatment of childhood hydrocephalus. J Pediatr 155 : 254-259.e1, 2009

30. Kulkarni AV, Riva-Cambrin J, Browd SR : Use of the ETV Success Score to explain the variation in reported endoscopic third ventriculostomy success rates among published case series of childhood hydrocephalus. J Neurosurg Pediatr 7 : 143-146, 2011

31. Kulkarni AV, Sgouros S, Constantini S; IIHS Investigators : International Infant Hydrocephalus Study: initial results of a prospective, multicenter comparison of endoscopic third ventriculostomy (ETV) and shunt for infant hydrocephalus. Childs Nerv Syst 32 : 1039-1048, 2016

32. Kumar $A$, Deopujari $C E$, Biyani $N$ : Utility of ventricular access in an acute deterioration after endoscopic third ventriculostomy. J Postgrad Med 57 : 123-125, 2011

33. Labidi M, Lavoie P, Lapointe G, Obaid S, Weil AG, Bojanowski MW, et al. : Predicting success of endoscopic third ventriculostomy: validation of the ETV Success Score in a mixed population of adult and pediatric patients.

J Neurosurg 123 : 1447-1455, 2015

34. Limbrick DD Jr, Baird LC, Klimo P Jr, Riva-Cambrin J, Flannery AM; Pediatric Hydrocephalus Systematic Review and Evidence-Based Guidelines Task Force : Pediatric hydrocephalus: systematic literature review and evidence-based guidelines. Part 4: Cerebrospinal fluid shunt or endoscopic third ventriculostomy for the treatment of hydrocephalus in children. J Neurosurg Pediatr 14 Suppl 1 : 30-34, 2014

35. Mahapatra A, Mehr S, Singh D, Tandon M, Ganjoo P, Singh H : Ostomy closure and the role of repeat endoscopic third ventriculostomy (re-ETV) in failed ETV procedures. Neurol India 59 : 867-873, 2011

36. Marton E, Feletti A, Basaldella L, Longatti P : Endoscopic third ventriculostomy in previously shunted children: a retrospective study. Childs Nerv Syst 26 : 937-943, 2010

37. Melikian A, Korshunov A : Endoscopic third ventriculostomy in patients with malfunctioning CSF-shunt. World Neurosurg 74 : 532-537, 2010

38. Morgenstern PF, Souweidane MM : Pineal region tumors: simultaneous endoscopic third ventriculostomy and tumor biopsy. World Neurosurg 79(2 Suppl) : S18.e9-e13, 2013

39. Ogiwara H, Dipatri AJ Jr, Alden TD, Bowman RM, Tomita T : Endoscopic third ventriculostomy for obstructive hydrocephalus in children younger than 6 months of age. Childs Nerv Syst $26: 343-347,2010$

40. Rangel-Castilla L, Barber S, Zhang YJ : The role of endoscopic third ven- 
triculostomy in the treatment of communicating hydrocephalus. World Neurosurg 77 : 555-560, 2012

41. Ransohoff J, Shulman K, Fishman RA : Hydrocephalus: A review of etiology and treatment. J Pediatr 56 : 399-411, 1960

42. Santamarta D, Martin-Vallejo J, Díaz-Alvarez A, Maillo A : Changes in ventricular size after endoscopic third ventriculostomy. Acta Neurochir (Wien) 150 : 119-127; discussion 127, 2008

43. Santamarta D, Onzain I, Blázquez JA, Gómez-Moreta JA, Morales F : Endoscopic third ventriculostomy: risk factors for failure and evolution of ventricular size. Neurocirugia (Astur) 15 : 248-256; discussion 256257, 2004

44. Schmitt PJ, Jane JA Jr : A lesson in history: the evolution of endoscopic third ventriculostomy. Neurosurg Focus 33 : E11, 2012

45. Schroeder C, Fleck S, Gaab MR, Schweim KH, Schroeder HW : Why does endoscopic aqueductoplasty fail so frequently? Analysis of cerebrospinal fluid flow after endoscopic third ventriculostomy and aqueductoplasty using cine phase-contrast magnetic resonance imaging. J Neurosurg $117: 141-149,2012$

46. Schwartz TH, Ho B, Prestigiacomo CJ, Bruce JN, Feldstein NA, Goodman RR : Ventricular volume following third ventriculostomy. J Neurosurg $91: 20-25,1999$

47. Schwartz TH, Yoon SS, Cutruzzola FW, Goodman RR : Third ventriculostomy: post-operative ventricular size and outcome. Minim Invasive Neurosurg 39 : 122-129, 1996
48. Shimizu T, Luciano MG, Fukuhara $\mathrm{T}$ : Role of endoscopic third ventriculostomy at infected cerebrospinal fluid shunt removal. J Neurosurg Pediatr $9: 320-326,2012$

49. Siomin V, Cinalli G, Grotenhuis A, Golash A, Oi S, Kothbauer K, et al. : Endoscopic third ventriculostomy in patients with cerebrospinal fluid infection and/or hemorrhage. J Neurosurg 97 : 519-524, 2002

50. Sufianov AA, Sufianova GZ, lakimov IA : Endoscopic third ventriculostomy in patients younger than 2 years: outcome analysis of 41 hydrocephalus cases. J Neurosurg Pediatr 5 : 392-401, 2010

51. Tamburrini G, Pettorini BL, Massimi L, Caldarelli M, Di Rocco C : Endoscopic third ventriculostomy: the best option in the treatment of persistent hydrocephalus after posterior cranial fossa tumour removal? Childs Nerv Syst 24 : 1405-1412, 2008

52. Teo C, Jones R : Management of hydrocephalus by endoscopic third ventriculostomy in patients with myelomeningocele. Pediatr Neurosurg 25 : 57-63; discussion 63, 1996

53. Tuli S, O'Hayon B, Drake J, Clarke M, Kestle J : Change in ventricular size and effect of ventricular catheter placement in pediatric patients with shunted hydrocephalus. Neurosurgery 45 : 1329-1335, 1999

54. Warf BC, Kulkarni AV : Intraoperative assessment of cerebral aqueduct patency and cisternal scarring: impact on success of endoscopic third ventriculostomy in 403 African children. J Neurosurg Pediatr 5 : 204209, 2010 